\title{
The Potential of Lactobacillus spp. for Modulating Oxidative Stress in the Gastrointestinal Tract
}

\author{
Yanzhuo Kong ${ }^{(}$, Kenneth J. Olejar*(D), Stephen L. W. On and Venkata Chelikani * \\ Department of Wine, Food and Molecular Biosciences, Lincoln University, Lincoln 7647, New Zealand; \\ Yanzhuo.Kong@lincolnuni.ac.nz (Y.K.); Stephen.On@lincoln.ac.nz (S.L.W.O.) \\ * Correspondence: Kenneth.OlejarJr@lincoln.ac.nz (K.J.O.); Venkata.Chelikani@lincoln.ac.nz (V.C.); \\ Tel.: +64-3-423-0600 (K.J.O.); +64-3-423-0623 (V.C.)
}

Received: 18 June 2020; Accepted: 7 July 2020; Published: 10 July 2020

check for updates

\begin{abstract}
The gastrointestinal (GI) tract is crucial for food digestion and nutrient absorption in humans. However, the GI tract is usually challenged with oxidative stress that can be induced by various factors, such as exogenous pathogenic microorganisms and dietary alterations. As a part of gut microbiota, Lactobacillus spp. play an important role in modulating oxidative stress in cells and tissues, especially in the GI tract. Oxidative stress is linked with excessive reactive oxygen species (ROS) that can be formed by a few enzymes, such as nicotinamide adenine dinucleotide phosphate (NADPH) oxidases (NOXs). The redox mechanisms of Lactobacillus spp. may contribute to the downregulation of these ROS-forming enzymes. In addition, nuclear factor erythroid 2 (NFE2)-related factor 2 (Nrf-2) and nuclear factor kappa B (NF-kB) are two common transcription factors, through which Lactobacillus spp. modulate oxidative stress as well. As oxidative stress is closely associated with inflammation and certain diseases, Lactobacillus spp. could potentially be applied for early treatment and amelioration of these diseases, either individually or together with prebiotics. However, further research is required for revealing their mechanisms of action as well as their extensive application in the future.
\end{abstract}

Keywords: oxidative stress; inflammation; Lactobacillus spp.; gastrointestinal (GI) tract

\section{Introduction}

The gastrointestinal (GI) tract, which comprises the oral cavity, esophagus, stomach, small intestine, large intestine, rectum as well as anus, plays an important role regarding food intake, digestion and nutrient absorption for humans and other mammals [1,2]. It is estimated that around 60 tons of foods will pass through the human GI tract during a normal lifetime, along with potential threats and challenges, which are primarily due to exogenous microbes [3]. There are few mechanisms that can protect the GI tract against those threats and challenges as well as maintain its healthy condition. For example, the GI epithelial cells and their secretion act as the major barrier which protects the GI tract from potential pathogens and toxicants [3,4].

Apart from that, gut microbiota, as a complex group of microorganisms colonizing the GI tract, are of significant importance with regard to health [5]. They may be considered as an extension of the human body, and contribute to the gut integrity [6], nutrient metabolism [7] and metabolic homeostasis [8]. In addition, gut microbiota are also important to the GI immune surveillance since they contribute to the development of the mucosal immune system in the GI tract [9]. Among the human gut microbiota, Lactobacillus spp. are a minor but necessary member, which have been revealed to be frequently implicated 
in multiple diseases, and are closely associated with human health [10]. In recent years, there has been an increasing number of Lactobacillus spp. consistently associated with the human GI tract [11]. A few studies have reported the beneficial role of Lactobacillus spp. regarding the balance they are able to bring to the gut microbiota. For example, supplementations of different combinations of L. fermentum and L. plantarum have been reported to affect diversity and functionality of the gut microbiota in mice [12]. According to $16 \mathrm{~S}$ rRNA (ribonucleic acid)-gene compositional data, the combination of two L. fermentum strains (GOS47 and GOS1) may contribute to the enhanced anti-inflammatory activity of gut microbiota. In addition, L. fermentum GOS57 and L. plantarum GOS42 altered the gut microbiota composition by decreasing the amount of Enterobacteriaceae and increasing the amount of Lactobacillus spp.

Oxidative stress is an imbalance between the production of reactive oxygen species (ROS) and their elimination, acted by protective mechanisms, namely antioxidant defenses [13]. Oxidative stress is implicated in the natural aging process and the pathogenesis of numerous diseases [14]. Some studies revealed that the low-grade inflammation involved in the pathogenesis of metabolic syndrome, such as diabetes, might be due to different levels of oxidative stress $[15,16]$. With regard to oxidative stress occurring in the GI tract, it has a close association with dietary structure and alterations of gut microbiota [13]. Importantly, diet is also a major factor in shaping the microbial colonization and their relative abundance in the human GI tract [17]. As a result of the beneficial role of gut microbiota, there has been an increasing focus regarding their positive impacts on oxidative stress and the pathogenesis of relevant diseases [18]. Thus, it is highly probable that the redox state of the GI tract could be maintained by gut microbiota, such as Lactobacillus spp. This review will discuss the potential of Lactobacillus spp. for modulating oxidative stress in the GI tract, with emphases on their redox mechanisms and possible application.

\section{Oxidative Stress}

\subsection{Reactive Oxygen Species (ROS)}

Oxidative stress describes the situation in which the antioxidant capacity and metabolic regulation of cells are overwhelmed due to excessive oxygen radicals, namely ROS [19,20]. The relatively narrow definition of ROS includes ozone $\left(\mathrm{O}_{3}\right)$, singlet oxygen $\left({ }^{1} \mathrm{O}_{2}\right)$ as well as reactive oxygen intermediates (ROI) involving hydroxyl radicals $\left({ }^{\bullet} \mathrm{OH}\right)$, hydrogen peroxide $\left(\mathrm{H}_{2} \mathrm{O}_{2}\right)$ and superoxide radical anion $\left(\mathrm{O}_{2}{ }^{\bullet-}\right)$ that are formed on the basis of incomplete reduction of molecular oxygen [21]. More generally, compounds such as hypochlorous $(\mathrm{HOCl})$, and incorporation of radicals like peroxyl $\left(\mathrm{ROO}^{\bullet}\right)$ or organic hydroperoxides $(\mathrm{ROOH})$, are also defined as ROS [22,23]. ROS could be regarded as natural by-products as a result of the metabolism of oxygen. Furthermore, ROS are important regarding the expression of some transcription factors and signal transduction molecules [24], and can also regulate cell adhesion and participate in intracellular signaling processes regarding apoptosis, cell overgrowth and others [25,26]. However, ROS are considered as damaging agents if they are formed excessively in living organisms.

As compared to exogenous sources of ROS, such as ultraviolet light and ionizing radiation, their endogenous sources are more crucial, which are implicated in a wide range of mechanisms within humans and other animals [27]. Various enzymes could be the intracellular sources of ROS. Cytosolic enzyme systems, typically nicotinamide adenine dinucleotide phosphate (NADPH) oxidases (NOXs), can generate $\mathrm{O}_{2}{ }^{\bullet-}$ through transferring an electron to a FAD (flavin adenine dinucleotide) cofactor and further passing it to a haem group, which is conducted by cytosolic domains of NOXs [28]. However, there might be different biological outcomes in response to the various expression of NOXs in different cells. In addition to NOXs, mitochondria are another major intracellular source of ROS, which produce ROS primarily through electron leakage from Complex I (NADH dehydrogenase) as well as Complex III (ubiquinol-cytochrome $c$ oxidoreductase), namely, two discrete points in the electron transporting chain $[29,30]$. Apart from the above, other endogenous sources of ROS are enzymes including xanthine 
oxidoreductase (XOR), cytochrome P450 family (CYPs), cyclooxygenase (COX) and lipoxygenase (LOX), as well as a few peroxisomal oxidases [31,32]. The ROS level normally remains very low inside the cells as a result of the well-developed antioxidant systems in eukaryotes, which can be classified as two categories, including ROS scavenging enzymes such as superoxide dismutase (SOD) and catalase, as well as non-enzymatic antioxidants like glutathione (GSH) and flavonoids [33]. However, the ROS level could increase due to many factors, such as suppression and inactivation of antioxidant enzymes, which will result in the imbalance between the production and elimination of ROS [25].

\subsection{Diet, Gut Microbiota and Oxidative Stress}

Oxidative stress could have deleterious impacts on various organs and systems throughout the body, such as the heart, kidney, liver and pancreas [26,34,35]. Apart from that, the GI tract is also where oxidative stress usually emerges, which is closely associated with alterations of the gut microbiota as well as diet [13]. Diet imparts a considerable impact on both colonization and abundance of the gut microbiota irrespective of the age. Different dietary components, such as dietary fiber, fat and minerals, can affect the gut microbiota differently; for example, dietary fiber, which contains resistant starch, could contribute to diversity of the gut microbiota [36]. In addition, it has been demonstrated that soluble fiber can maintain the balance of the gut microbial ecosystem [37]. On the contrary, fat and salt usually contribute to negative effects on gut microbiota. It has been extensively reported that the high-fat diet can promote oxidative stress and therefore cause organ damage [35,38]. With regard to the GI tract, the alteration of dietary fat intake (from low to high) in mice was able to shift the structure and gene expression of their gut microbiota within one day [39]. Fleissner et al. [40] reported that the proportion of intestinal Firmicutes increased with the increase of dietary fat consumption in mice, which was majorly due to the proliferation of the Erysipelotrichaceae (up to $48.8 \%$ of total $16 \mathrm{~S}$ rRNA sequences in the high-fat group), namely, one family within the phylum Firmicutes. Apart from high-fat diet, a high-salt diet may also lead to oxidative stress in different organs, such as the liver [34]. The gut microbiota are also sensitive to excessive salt intake. Bier et al. [41] observed that a high-salt diet increased the abundance of taxa from the Erwinia genus, including the families of Christensenellaceae and Corynebacteriaceae, whereas it reduced the abundance of taxa from the Anaerostipes genus. They suggested that these changes regarding gut microbial composition were potentially associated with the changes of short chain fatty acids (SCFAs) production. As an important group of mediators involved in blood pressure (BP) regulation, SCFAs may play a role in the complex diet-gut-BP interaction, which is linked to human health.

As mentioned above, the gut microbiota are sensitive to dietary change. Therefore, they are considered as a key part involved in the variation of oxidative stress in the GI tract as well as the diseases caused indirectly. Qiao et al. [13] reported that the development of metabolic syndrome could be affected by the gut microbiota alterations in relation to dietary changes, and this could be indirectly associated with changes of the redox state in the GI tract. Luca et al. [42] also reported that the imbalanced gut microbial community, namely dysbiosis, could potentially contribute to the development of depression, type-2 diabetes mellitus as well as Alzheimer's disease, of which oxidative stress and inflammation are involved. Since gut microbiota play a crucial role with regard to the diet-induced oxidative stress in the GI tract, it is necessary to further investigate this field.

\subsection{Diseases Associated with Oxidative Stress}

The detrimental impacts of oxidative stress can impact the whole body. This is because the smallest structural and functional unit, namely the cell, is directly affected by oxidative stress, in which membranes, lipoproteins, proteins, lipids, deoxyribonucleic acid (DNA), RNA as well as ribosomes are majorly involved [43-45]. Oxidative stress is closely associated with many diseases, especially chronic and 
degenerative diseases, such as cancer. Cancer describes a group of diseases that involve the growth of malignant tumors or abnormal cells with the capacity to invade or spread to other parts of the body, and destroy body tissue [46]. Various types of cancer have been reported to be linked to oxidative stress, including liver cancer, colon cancer, pancreatic cancer, skin cancer, breast cancer, bladder cancer and prostate cancer [47]. In addition to cancer, several neurodegenerative diseases, such as the commonly known Parkinson's disease and Alzheimer's disease, have also been linked to oxidative stress [48,49]. Besides, oxidative stress is involved in the pathogenesis of many other diseases as well, either chronic or acute, which include cardiovascular diseases [50,51], insulin resistance [52], pulmonary fibrosis [53,54], chronic obstructive pulmonary disease (COPD) [55], muscle protein degradation [56], renal dysfunction [57], stroke and others [58].

Interestingly, inflammation is a common cause of many chronic diseases; more specifically, it is a biological process involved in the relevant pathogenesis since oxidative stress can activate many transcription factors, and therefore vary the expression of certain genes involved in inflammatory pathways [59]. For example, the level of oxidative stress-induced inflammation could be increased through the nuclear factor kappa B (NF- $\mathrm{kB}$ ) signaling [60]. With regard to diseases in the GI tract, inflammatory bowel disease (IBD) is typical as an oxidative stress-associated disease. IBD describes a group of conditions or disorders resulting in prolonged inflammation within the GI tract [61]. There are two common types of IBD, which are Crohn's Disease (CD) and Ulcerative Colitis (UC) [62]. It has been reported that oxidative stress is a potential etiological factor contributing to IBD in which the ROS levels are abnormally high [63]. Some studies reported the possible association between this kind of oxidative stress and the composition of gut microbiota, to which the dietary structure may be linked [5,10]. Overall, diseases that are linked to oxidative stress could be induced throughout the body where cells and tissues are damaged, and inflammation is usually involved in the relevant pathogenesis.

\section{Lactobacillus spp.}

Lactobacillus spp. are a major group of lactic acid bacteria (LAB), which are Gram-positive, facultatively anaerobic, rod-shaped as well as non-sporulating [64]. They are both oxidase- and catalase-negative, and can ferment carbohydrates as well as hydrolyze esculin [65]. Lactobacillus spp. can be isolated from many fermented products, such as dairy products and pickles [66,67]. Apart from that, Lactobacillus spp. are also regular flora colonizing the GI tract and the female genital tract, where they contribute to partial inhibition of pathogenic microorganisms due to the production of lactic acid [65]. In addition, they are common microbial species that inhabit the human mouth, which has been reported to be associated with dental caries [68].

The genus Lactobacillus is currently composed of 253 species, for which the names are validly published [69]. The common species of Lactobacillus are various depending on different kinds of animals, such as herbivores, carnivores and omnivores, which are classified by food they eat [70]. For example, the dominant Lactobacillus spp. found in carnivores are L. johnsonii, L. reuteri, L. salivarius, L. vaginalis as well as L. ingluviei, which are not predominant species in omnivores and herbivores [70]. Moreover, the colonization of Lactobacillus spp. also varies within the human body, as shown in Table 1. In general, the prevalent Lactobacillus spp. are various with regard to different parts of the human body, although some of them are predominant in more than one place, especially within the GI tract, such as L. acidophilus, L. plantarum and L. fermentum. 
Table 1. Common Lactobacillus spp. colonizing the human body.

\begin{tabular}{|c|c|c|c|}
\hline Parts o & han Body & Common Lactobacillus spp. & References \\
\hline \multirow{3}{*}{ The GI tract } & Mouth & $\begin{array}{l}\text { L. acidophilus, L. gasseri, } \\
\text { L. fermentum, L. crispatus, } \\
\text { L. delbrueckii, L. salivarius, } \\
\text { L. paracasei, L. plantarum, } \\
\text { L. rhamnosus and L. oris; }\end{array}$ & {$[71,72]$} \\
\hline & Stomach mucosa & $\begin{array}{l}\text { L. gastricus, L. antri, } \\
\text { L. kalixensis, L. reuteri, } \\
\text { and L. ultunensis; }\end{array}$ & [73] \\
\hline & Intestine & $\begin{array}{l}\text { L. acidophilus, L. salivarius, } \\
\text { L. casei, L. plantarum, } \\
\text { L. fermentum, L. reuterii, } \\
\text { L. brevis and L. rhamnosus; }\end{array}$ & {$[74,75]$} \\
\hline \multicolumn{2}{|c|}{ The female genital tract } & $\begin{array}{l}\text { L. crispatus, L. gasseri, } \\
\text { L. jensenii, L. vaginalis } \\
\text { and L. iners. }\end{array}$ & [76] \\
\hline
\end{tabular}

\section{Redox Role of Lactobacillus spp.}

The beneficial and functional properties of Lactobacillus spp. have been extensively reported in recent years. Apart from their contribution to diversity and functionality of the gut microbiota, it has also been reported that they are associated with improved physiological function and cognitive ability $[12,77,78]$. In addition, the ameliorative impact of Lactobacillus spp. on oxidative stress has also been commonly investigated and discussed [79,80]. Although there are many well-defined mechanisms regarding ROS production and its relation to the gut microbiota, the redox role and relevant mechanisms of Lactobacillus spp. are still being investigated [81]. Below, we focus on the potential redox role of Lactobacillus spp. in modulating oxidative stress, particularly in the GI tract, based on recent research outputs.

\subsection{Oxidative Stress Resistance Genes and Proteins}

Genes and proteins that are resistant to oxidative stress are pivotal for the redox mechanisms of Lactobacillus spp., since they are directly involved in the signaling pathways activated by ROS [82]. The common genes and proteins in Lactobacillus spp., which contribute to resistance towards oxidative stress, are summarized in Table 2. The role played by thioredoxin, thioredoxin reductase as well as their encoding genes against oxidative stress, which is called a thioredoxin antioxidant system, has been highlighted in several studies, as shown in Table 2. Oxidative resistance genes and proteins are possessed by a limited number of Lactobacillus spp. Thus, transformation of oxidative stress resistance genes into valuable probiotic strains, which are deficient in such genes, has become a useful research tool. For example, An et al. [83] co-expressed SOD and catalase genes ( $\operatorname{sodA}$ from S. thermophilus and katA from L. sakei) in L. rhamnosus, a valuable probiotic starter culture in industrial fermentation but which is susceptible to oxidative stress. Co-expression of two genes remarkably improved the strains' resistance capacity against oxidative stress. The survival ratio of L. rhamnosus was 400-fold higher than those expressed kat $A$ only. Similarly, co-expression of catalase and bile salt hydrolase genes (katA from L. sakei and bsh1 from L. plantarum) in L. casei also significantly improved their resistance capacity towards oxidative stress and bile salts stress, which could be beneficial for strain performance during gastrointestinal transit and relevant processes [84]. 
Table 2. Common oxidative stress resistance genes and proteins found in Lactobacillus spp.

\begin{tabular}{|c|c|c|c|}
\hline Lactobacillus spp. & Genes/Locus Tag & Encoded Proteins & References \\
\hline L. plantarum & $\begin{array}{ll} & \text { trxB1 } \\
& \text { KatE1 } \\
& \\
\text { plasmid } & \\
\text { pCAUH203 } & \end{array}$ & $\begin{array}{c}\text { thioredoxin reductase } \\
\text { heme-dependent catalase } \\
\text { thioredoxin reductase } \\
\text { thioredoxin } \\
\text { DNA protection protein } \\
\mathrm{NAD}(\mathrm{P}) / \mathrm{FAD}-\text { dependent oxidoreductase } \\
\text { DsbA family oxidoreductase }\end{array}$ & $\begin{array}{l}{[85]} \\
{[86]}\end{array}$ \\
\hline L. casei & $\begin{array}{c}\operatorname{tr} x A 1 \\
\operatorname{tr} x A 2 \\
\operatorname{tr} x B\end{array}$ & $\begin{array}{l}\text { thioredoxin } \\
\text { thioredoxin reductase }\end{array}$ & [88] \\
\hline L. casei Shirota & hprA1 & HprA1* & [89] \\
\hline L. sakei & katA & catalase & {$[83,84]$} \\
\hline L. brevis & KatE2 & heme-dependent catalase & [86] \\
\hline L. helveticus & uvrA & UvrA & [90] \\
\hline L. reuteri & $\begin{array}{l}\text { orf01,513 } \\
\text { orf00,076, orf01,790 } \\
\text { orf00,102 } \\
\text { orf00,146 } \\
\text { orf00,594 } \\
\text { orf00,178 }\end{array}$ & $\begin{array}{c}\text { glutathione reductase } \\
\text { NADH oxidase } \\
\text { NADH-dependent flavin reductase } \\
\text { NADH-dependent oxidoreductase } \\
\text { NADH dehydrogenase } \\
\text { NADH-flavin reductase }\end{array}$ & [91] \\
\hline
\end{tabular}

${ }^{*}$ Hpr: hydrogen peroxide resistance.

\subsection{Redox Mechanisms}

\subsubsection{Nrf-2 Transcription Factor}

Nrf-2 stands for nuclear factor erythroid 2 (NFE2)-related factor 2, which is an emerging transcription factor that takes part in the modulation of cellular oxidative stress [92]. With regard to the genetic aspect of Nrf-2, the expression of a number of antioxidant response element (ARE)-containing genes plays a crucial role in the cellular defense mechanisms against oxidative stress [93,94]. On the other hand, the pathway which consists of Kelch-like ECH-associated protein 1 (Keap 1) and Nrf-2 is also important for modulating oxidative stress, which is majorly based on the modification of reactive cysteine residues of Keap 1 [95]. Furthermore, glutathione peroxidase (GPx) and catalase that are implicated in Nrf-2 signaling may contribute to the modulation of oxidative stress as well [96,97].

Li et al. [98] elucidated a possible mechanism for a L. helveticus strain regarding its potential preventive effect on aging-related oxidative stress in a mouse model, which was through the Nrf-2 signaling. According to the observed species index, administration of the L. helveticus strain significantly reversed the impact of D-galactose-induced oxidative stress on the gut microbiota, returning the gut microbiome composition to that more closely resembling the control group. Furthermore, administration of the strain at $3 \times 10^{8}$ colony-forming units (CFU) resulted in roughly double the butyrate level in the cecal contents compared to the group treated with D-galactose only. Similar findings have been reported by Finamore et al. [99] as well, suggesting the significance of Nrf-2 for the redox role of Lactobacillus spp. They investigated the redox protective effects of L. casei strain Shirota (a well-established isolate used in commercial yogurt manufacture) on oxidative and inflammatory stresses in the human intestinal Caco-2/TC7 cell line. Based on their results, L. casei Shirota helped prevent cellular ROS accumulation as well as membrane barrier disruption. They firstly suggested a redox mechanism of L. casei Shirota, 
for which both the modulation of Nrf-2/Keap 1 signaling and inhibition of the NF- $\mathrm{KB}$ inflammatory pathway contributed to the protective effect, in relation to the regulation of p65 phosphorylation and GPx2 activity. In general, Nrf-2 seems to be an important transcription factor that some Lactobacillus spp. commonly regulates intestinal oxidative stress through.

\subsubsection{NF- $\mathrm{kB}$ Transcription Factor}

There is a close association between NF- $\mathrm{kB}$ and Nrf-2 transcription factors, which depends on cell types where oxidative stress emerges. Generally, the absence of Nrf-2 can result in increased NF- $k B$ activity, which contributes to more aggressive inflammation [100]. Similarly, NF- $\kappa B$ can also mediate the transcriptional activity of Nrf-2 [101]. The activation of NF- $\mathrm{kB}$ is usually regulated by tumor necrosis factor alpha (TNF- $\alpha$ ), lipopolysaccharide (LPS), as well as interleukin 1 (IL-1) [102]. NF- $\kappa B$ plays both antioxidant and prooxidant roles in response to oxidative stress $[103,104]$. Normal activation of NF-kB and the relevant modulation of autophagy can result in protective effects, such as less ROS accumulation. In contrast, cells could be more susceptible to oxidative stress if NF- $\mathrm{kB}$ and autophagy are inhibited, with enhanced ROS formation, lipid peroxidation and protein oxidation, which are induced by TNF- $\alpha[103,104]$.

In addition to Nrf-2, NF- $\mathrm{BB}$ may be another transcription factor which plays an important role in the redox mechanisms of Lactobacillus spp. Chen et al. [105] reported a potential association between the inhibition of NF- $\mathrm{kB}$ p 65 translocation administered by L. acidophilus and attenuated atherosclerotic oxidative stress in a mouse model. Similarly, a L. brevis strain has also been reported that can alleviate the intestinal oxidative stress through the interplay of NF- $\mathrm{kB}$ and MAPK (mitogen-activated protein kinase) pathways in a mouse model [106]. Apart from the above, the NF- $\kappa B$ is potentially implicated in the redox mechanisms of recombinant Lactobacillus strains as well, where certain anti-oxidative stress response genes are transformed and expressed. Hou et al. [107] reported the ameliorative effect of $\operatorname{sod} A$ recombinant L. fermentum on intestinal oxidative stress that was induced by trinitrobenzene sulfonic acid (TNBS) in a colitis mouse model. By inhibiting the activity of NF- $\mathrm{B}$ p 65 subunit, they observed significantly higher survival rate, less lipid peroxidation and less expression of pro-inflammatory cytokines in the mouse model, which indicated decreased oxidative stress compared to mice without administration of the recombinant strain. Although many studies have reported the potential redox role of NF- $\mathrm{kB}$ involved in Lactobacillus spp., its molecular mechanisms still remain unknown at the current stage, for which further research is required.

\subsubsection{Others}

With regard to other mechanisms, Toral et al. [108] reported a successful prevention of oxidative stress-associated endothelial dysfunction and hypertension in mice, which was achieved by a L. fermentum strain. It could be possibly due to downregulation of NOXs and prevention of endothelial nitric oxide synthase (eNOS) uncoupling, since both mechanisms are involved in the formation process of ROS [109]. Wang et al. [110] also highlighted the importance of the downregulation of pro-inflammatory cytokines, such as TNF- $\alpha$, in modulating oxidative stress-induced UC in a mouse model. Apart from the redox role of the strain itself, the functional products derived from Lactobacillus spp. might also contribute to the redox mechanisms. For example, exopolysaccharide (EPS) that are produced by Lactobacillus spp. may have the potential to alleviate oxidative stress. Li et al. [111] evaluated the ameliorative impact of EPS, which was secreted by a L. helveticus strain, on oxidative stress. Both in vitro and in vivo tests showed positive effects of the EPS on oxidative stress, especially towards hepatic oxidative stress, for which the manipulation of gut microbiota composition played an important role. 


\section{Potential Application}

\subsection{Early Treatment towards Diseases in the GI Tract}

Lactobacillus spp. have the potential to be applied as an early treatment approach for many oxidative stress-associated diseases, notably for diseases of the GI tract. As stated before, inflammation is a common biological process involved in the pathogenesis of many diseases induced by oxidative stress, such as IBD. Therefore, the anti-inflammatory activity of Lactobacillus spp. is regarded as a crucial aspect regarding the modulation of diseases in the GI tract [112]. In early studies, both L. plantarum and L. fermentum have been reported to have the potential for early treatment towards inflammation and colitis in the GI tract $[107,113]$. Recently, Le and Yang [114] reported that IBD could be potentially prevented and managed by L. plantarum, in which the modulation of the ratio of T helper cell 1 (Th1) and T helper cell 2 (Th2) plays an important role. In addition to IBD, it has been reported that CD, which was induced by either TNBS or a mucosal pathogen Citrobacter rodentium, could be potentially ameliorated by L. reuteri in a mouse model [115]. Wang et al. [110] investigated the anti-inflammatory effect of L. plantarum strain ZDY2013 and B. bifidum WBIN03 strains on dextran sodium sulphate (DSS)-induced UC in a mouse model. This study demonstrated substantive anti-inflammatory capacity against the DSS-induced UC in mice compared to a HT-29 cell model, which was based on downregulation of pro-inflammatory cytokines and upregulation of antioxidant factors during the transcription process. Overall, the supplementation of probiotics, such as Lactobacillus spp., has the potential to relieve the oxidative stress-induced inflammation in the GI tract, which could be further considered as an early treatment approach maintaining the redox balance of the GI tract.

\subsection{Early Treatment towards Other Diseases}

Many studies have discussed the in vitro and in vivo functional properties of Lactobacillus spp. towards oxidative stress-related diseases. As probiotics, Lactobacillus spp. have already been reported that can successfully prevent or ameliorate oxidative stress-induced inflammation in some organs, such as liver [116]. For example, the amount of SOD and glutathione in weanling piglets could increase due to L. fermentum administration, with the enhanced capacity to inhibit $\mathrm{O}_{2}{ }^{\bullet-}$ formation in muscle and liver, which can contribute to the modulation of oxidative stress in relevant organs [117]. Recent research also reported the preventive capacity of a L. plantarum strain, administered orally, on Di-2-ethylhexyl phthalate (DEHP)-induced testicular damage in mice [118]. In addition, few oxidative stresses-induced cardiovascular diseases and metabolic syndrome may be alleviated by Lactobacillus spp. as well. Chen et al. [105] reported the potential attenuation ability of L. acidophilus ATCC 4356 on atherosclerotic progression in Apolipoprotein-E knockout mice. Based on their results, L. acidophilus administration led to decreased atherosclerotic lesion size without changing the body weights and profiles of serum lipid. Apart from cardiovascular diseases such as atherosclerosis, the association between Lactobacillus spp.- and oxidative stress-related metabolic disorders have also been extensively studied. It has been commonly reported that type-2 diabetes mellitus could be ameliorated by probiotic supplementation, such as L. rhamnosus $[97,119]$. Furthermore, Lactobacillus spp. might also be associated with the mitigation of vascular oxidative stress involved in hypertension pathogenesis [120].

In other research, Huang et al. [121] suggested a potential application of L. plantarum as an ergogenic aid for health promotion and physiological adaptions towards exercise. They investigated the beneficial role of L. plantarum on high-intensity exercise that is associated with oxidative stress and can further induce inflammation and muscular damage. Based on their results, L. plantarum supplementation significantly alleviated oxidative stress in relation to exercise, where a $55 \%$ increase of anti-inflammation cytokines (IL-10) and a 6-13\% decrease of pro-inflammation cytokines (IL-6, IL-8 and TNF- $\alpha$ ) were observed. Besides, 
Lactobacillus spp. can also be used for the alleviation of metal toxicity. Yu et al. [122] reported the potential protective role of $L$. plantarum against aluminum-induced oxidative stress as well as inflammatory response both in vitro (HT-29 cells, intestinal tissues) and in vivo. The levels of pro-inflammatory cytokines (TNF- $\alpha$, IL-6 and IL-1 $\beta$ ) were measured as indicators. According to their results, L. plantarum was able to partially restore the levels of three cytokines increased due to aluminum exposure in both in vitro and in vivo experiments, except the IL-6 levels in the colon. Overall, Lactobacillus spp. could be potentially applied to a wide range of oxidative stress-associated diseases, in addition to those occurring in the GI tract.

\subsection{Co-administration with Prebiotics}

Apart from applying Lactobacillus spp. alone, co-administration of probiotics and prebiotics seems to be an emerging research focus in recent years. Palócz et al. [113] reported that the simultaneous application of chlorogenic acid and L. plantarum showed a great potential against lipopolysaccharide (LPS)-induced oxidative stress and inflammation in intestinal epithelial IPEC-J2 cells. Similarly, Deol et al. [123] investigated the effect of co-administration of ginger extract and L. acidophilus on intestinal oxidative stress and inflammation in a mouse model. They observed that $0.4 \% w / v$ ginger extract could largely increase the amount of L. acidophilus during a 48 to $96 \mathrm{~h}$ incubation. In addition, the lipid peroxidation level significantly decreased in the co-administration group compared to the control groups where strains and ginger extract were assigned individually. Therefore, co-administration of Lactobacillus spp. and suitable prebiotics could be a promising approach in modulating oxidative stress and oxidative stress-induced inflammation in the GI tract. However, further research needs to be conducted to demonstrate consistent positive impacts on both oxidative stress and relevant diseases.

\section{Conclusions}

To conclude, Lactobacillus spp. show potential for the modulation of oxidative stress in cells and tissues throughout the human body, especially in the GI tract, where they may be found naturally. Due to their apparent role in redox reactions, Lactobacillus spp. could be utilized as probiotic supplementation for amelioration of many oxidative stress-induced diseases, such as inflammation in the GI tract and certain other chronic diseases. Furthermore, Lactobacillus spp. could also be administrated together with suitable prebiotics, which may result in better antioxidative and anti-inflammatory profiles. Despite the promising ameliorative impact of Lactobacillus spp., their mechanisms of action are still incompletely understood. Therefore, further investigations are needed in this regard, ultimately culminating in clinical research to ratify the extent of the possible benefits that may be realized with the use of Lactobacillus spp. to treat human illnesses that arise from oxidative stress.

Author Contributions: Conceptualization, Y.K. and V.C.; resources, K.J.O. and V.C.; writing-original draft preparation, Y.K.; writing-review and editing, K.J.O., S.L.W.O. and V.C.; visualization, Y.K., K.J.O. and V.C.; supervision, V.C., K.J.O. and S.L.W.O.; project administration, V.C.; funding acquisition, V.C. and K.J.O. All authors have read and agreed to the published version of the manuscript.

Funding: This research was funded by Lincoln University, New Zealand, internal researcher funding.

Conflicts of Interest: The authors declare no conflict of interest.

\section{References}

1. Yoder, S.M.; Kindel, T.L.; Tso, P. Using the Lymph Fistula Rat Model to Study Incretin Secretion. In Vitamins $\mathcal{E}$ Hormones; Academic Press: Cambridge, MA, USA, 2010; Volume 84, pp. 221-249.

2. Kararli, T.T. Comparison of the gastrointestinal anatomy, physiology, and biochemistry of humans and commonly used laboratory animals. Biopharm. Drug Dispos. 1995, 16, 351-380. [CrossRef] [PubMed] 
3. Bengmark, S. Ecological control of the gastrointestinal tract. The role of probiotic flora. Gut 1998, 42, 2-7. [CrossRef] [PubMed]

4. Jepson, M.A. Gastrointestinal Tract. In Adverse Effects of Engineered Nanomaterials; Academic Press: Cambridge, MA, USA, 2012; pp. 209-224. [CrossRef]

5. Tomasello, G.; Mazzola, M.; Leone, A.; Sinagra, E.; Zummo, G.; Farina, F.; Damiani, P.; Cappello, F.; Geagea, A.G.; Jurjus, A.; et al. Nutrition, oxidative stress and intestinal dysbiosis: Influence of diet on gut microbiota in inflammatory bowel diseases. Biomed. Pap. 2016, 160, 461-466. [CrossRef] [PubMed]

6. Natividad, J.M.M.; Verdu, E.F. Modulation of intestinal barrier by intestinal microbiota: Pathological and therapeutic implications. Pharmacol. Res. 2013, 69, 42-51. [CrossRef]

7. Rowland, I.; Gibson, G.; Heinken, A.; Scott, K.; Swann, J.; Thiele, I.; Tuohy, K. Gut microbiota functions: Metabolism of nutrients and other food components. Eur. J. Nutr. 2018, 57. [CrossRef]

8. Bull, M.J.; Plummer, N.T. Part 1: The human gut microbiome in health and disease. Integr. Med. (Boulder) 2014, 13, 17-22.

9. Thursby, E.; Juge, N. Introduction to the human gut microbiota. Biochem. J. 2017, 474, 1823-1836. [CrossRef]

10. Heeney, D.D.; Gareau, M.G.; Marco, M.L. Intestinal Lactobacillus in health and disease, a driver or just along for the ride? Curr. Opin. Biotechnol. 2018, 49, 140-147. [CrossRef]

11. Rossi, M.; Martinez-Martinez, D.; Amaretti, A.; Ulrici, A.; Raimondi, S.; Moya, A. Mining metagenomic whole genome sequences revealed subdominant but constant Lactobacillus population in the human gut microbiota. Environ. Microbiol. Rep. 2016, 8, 399-406. [CrossRef]

12. Linninge, C.; Xu, J.; Bahl, M.I.; Ahrné, S.; Molin, G. Lactobacillus fermentum and Lactobacillus plantarum increased gut microbiota diversity and functionality, and mitigated Enterobacteriaceae, in a mouse model. Benef. Microbes 2019, 10, 413-424. [CrossRef]

13. Qiao, Y.; Sun, J.; Ding, Y.; Le, G.; Shi, Y. Alterations of the gut microbiota in high-fat diet mice is strongly linked to oxidative stress. Appl. Microbiol. Biotechnol. 2013, 97, 1689-1697. [CrossRef]

14. Dasgupta, A.; Klein, K. Chapter 10-Role of Oxidative Stress in Neurodegenerative Diseases and Other Diseases Related to Aging. In Antioxidants in Food, Vitamins and Supplements; Dasgupta, A., Klein, K., Eds.; Elsevier: San Diego, CA, USA, 2014; pp. 167-184. [CrossRef]

15. Wellen, K.E.; Fucho, R.; Gregor, M.F.; Furuhashi, M.; Morgan, C.; Lindstad, T.; Vaillancourt, E.; Gorgun, C.Z.; Saatcioglu, F.; Hotamisligil, G.S. Coordinated Regulation of Nutrient and Inflammatory Responses by STAMP2 Is Essential for Metabolic Homeostasis. Cell 2007, 129, 537-548. [CrossRef] [PubMed]

16. Esser, N.; Legrand-Poels, S.; Piette, J.; Scheen, A.J.; Paquot, N. Inflammation as a link between obesity, metabolic syndrome and type 2 diabetes. Diabetes Res. Clin. Pract. 2014, 105, 141-150. [CrossRef]

17. Donaldson, G.P.; Lee, S.M.; Mazmanian, S.K. Gut biogeography of the bacterial microbiota. Nat. Rev. Microbiol. 2015, 14, 20-32. [CrossRef] [PubMed]

18. Dam, B.; Misra, A.; Banerjee, S. Role of Gut Microbiota in Combating Oxidative Stress. In Oxidative Stress in Microbial Diseases; Chakraborti, S., Chakraborti, T., Chattopadhyay, D., Shaha, C., Eds.; Springer: Singapore, 2019; pp. 43-82. [CrossRef]

19. Gagné, F. Biochemical Ecotoxicology: Principles and Methods; Elsevier: Amsterdam, The Netherlands, $2014 ;$ pp. 1-257. [CrossRef]

20. Lushchak, V.I. Environmentally induced oxidative stress in aquatic animals. Aquat. Toxicol. 2011, 101, 13-30. [CrossRef] [PubMed]

21. Nathan, C.; Ding, A. Snapshot: Reactive oxygen intermediates (ROI). Cell 2010, 140, 951.e2. [CrossRef]

22. Halliwell, B. Oxidative stress and neurodegeneration: Where are we now? J. Neurochem. 2006, 97, 1634-1658. [CrossRef]

23. Liou, G.Y.; Storz, P. Reactive oxygen species in cancer. Free Radic. Res. 2010, 44, 479-496. [CrossRef]

24. Winterbourn, C.C. Reconciling the chemistry and biology of reactive oxygen species. Nat. Chem. Biol. 2008, 4, 278-286. [CrossRef] 
25. Lushchak, V.I. Free radicals, reactive oxygen species, oxidative stress and its classification. Chem. Biol. Interact. 2014, 224, 164-175. [CrossRef]

26. Ogura, S.; Shimosawa, T. Oxidative stress and organ damages. Curr. Hypertens. Rep. 2014, 16. [CrossRef] [PubMed]

27. Finkel, T.; Holbrook, N.J. Oxidants, oxidative stress and the biology of ageing. Nature 2000, 408, $239-247$. [CrossRef] [PubMed]

28. Nathan, C.; Cunningham-Bussel, A. Beyond oxidative stress: An immunologist's guide to reactive oxygen species. Nat. Rev. Immunol. 2013, 13, 349-361. [CrossRef] [PubMed]

29. Turrens, J.F. Mitochondrial formation of reactive oxygen species. J. Physiol. 2003, 552, 335-344. [CrossRef] [PubMed]

30. Finkel, T. Signal transduction by reactive oxygen species. J. Cell Biol. 2011, 194, 7-15. [CrossRef]

31. Kawahara, B.T.; Quinn, M.T.; Lambeth, J.D. Molecular evolution of the reactive oxygen-generating NADPH oxidase (Nox/Duox) family of enzymes. BMC Evol. Biol. 2007, 7. [CrossRef]

32. Xu, J.; Chen, L.; Li, L. Pannexin hemichannels: A novel promising therapy target for oxidative stress related diseases. J. Cell Physiol. 2018, 233, 2075-2090. [CrossRef]

33. Das, K.; Roychoudhury, A. Reactive oxygen species (ROS) and response of antioxidants as ROS-scavengers during environmental stress in plants. Front. Environ. Sci. 2014, 2. [CrossRef]

34. Uetake, Y.; Ikeda, H.; Irie, R.; Tejima, K.; Matsui, H.; Ogura, S.; Wang, H.; Mu, S.; Hirohama, D.; Ando, K.; et al. High-salt in addition to high-fat diet may enhance inflammation and fibrosis in liver steatosis induced by oxidative stress and dyslipidemia in mice. Lipids Health Dis. 2015, 14. [CrossRef]

35. Sudhakara, G.; Mallaiah, P.; Rajendran, R.; Saralakumari, D. Caralluma fimbriata and metformin protection of rat pancreas from high fat diet induced oxidative stress. Biotech. Histochem. 2018, 93, 177-187. [CrossRef]

36. Walker, A.W.; Ince, J.; Duncan, S.H.; Webster, L.M.; Holtrop, G.; Ze, X.; Brown, D.; Stares, M.D.; Scott, P.; Bergerat, A.; et al. Dominant and diet-responsive groups of bacteria within the human colonic microbiota. ISME J. 2011, 5, 220-230. [CrossRef] [PubMed]

37. Calder, P.C. Omega-3 polyunsaturated fatty acids and inflammatory processes: Nutrition or pharmacology? Br. J. Clin. Pharmacol. 2013, 75, 645-662. [CrossRef] [PubMed]

38. Sarna, L.K.; Sid, V.; Wang, P.; Siow, Y.L.; House, J.D.; Karmin, O. Tyrosol Attenuates High Fat Diet-Induced Hepatic Oxidative Stress: Potential Involvement of Cystathionine $\beta$-Synthase and Cystathionine $\gamma$-Lyase. Lipids 2016, 51, 583-590. [CrossRef]

39. Turnbaugh, P.J.; Ridaura, V.K.; Faith, J.J.; Rey, F.E.; Knight, R.; Gordon, J.I. The effect of diet on the human gut microbiome: A metagenomic analysis in humanized gnotobiotic mice. Sci. Transl. Med. 2009, 1. [CrossRef] [PubMed]

40. Fleissner, C.K.; Huebel, N.; Abd El-Bary, M.M.; Loh, G.; Klaus, S.; Blaut, M. Absence of intestinal microbiota does not protect mice from diet-induced obesity. Br. J. Nutr. 2010, 104, 919-929. [CrossRef] [PubMed]

41. Bier, A.; Braun, T.; Khasbab, R.; Di Segni, A.; Grossman, E.; Haberman, Y.; Leibowitz, A. A high salt diet modulates the gut microbiota and short chain fatty acids production in a salt-sensitive hypertension rat model. Nutrients 2018, 10, 1154. [CrossRef] [PubMed]

42. Luca, M.; Mauro, M.D.; Mauro, M.D.; Luca, A. Gut microbiota in Alzheimer's disease, depression, and type 2 diabetes mellitus: The role of oxidative stress. Oxid. Med. Cell. Longev. 2019, 2019. [CrossRef]

43. Halliwell, B.; Whiteman, M. Measuring reactive species and oxidative damage in vivo and in cell culture: How should you do it and what do the results mean? Br. J. Pharmacol. 2004, 142, 231-255. [CrossRef]

44. Collins, A.R.; Horváthová, E. Oxidative DNA damage, antioxidants and DNA repair: Applications of the comet assay. Biochem. Soc. Trans. 2001, 29, 337-341. [CrossRef]

45. Shcherbik, N.; Pestov, D.G. The impact of oxidative stress on ribosomes: From injury to regulation. Cells 2019, 8, 1379. [CrossRef]

46. Lee, D.J.; Kang, S.W. Reactive oxygen species and tumor metastasis. Mol. Cells 2013, 35, 93-98. [CrossRef] [PubMed] 
47. Dasgupta, A.; Klein, K. Chapter 8-Oxidative Stress and Cancer. In Antioxidants in Food, Vitamins and Supplements; Dasgupta, A., Klein, K., Eds.; Elsevier: San Diego, CA, USA, 2014; pp. 129-150. [CrossRef]

48. Andersen, J.K. Oxidative stress in neurodegeneration: Cause or consequence? Nat. Rev. Neurosci. 2004, 10, S18-S25. [CrossRef] [PubMed]

49. Calabrese, V.; Guagliano, E.; Sapienza, M.; Mancuso, C.; Butterfield, D.A.; Stella, A.M. Redox regulation of cellular stress response in neurodegenerative disorders. Ital. J. Biochem. 2006, 55, 263-282. [PubMed]

50. Pizzino, G.; Irrera, N.; Cucinotta, M.; Pallio, G.; Mannino, F.; Arcoraci, V.; Squadrito, F.; Altavilla, D.; Bitto, A. Oxidative Stress: Harms and Benefits for Human Health. Oxid. Med. Cell. Longev. 2017, 2017. [CrossRef] [PubMed]

51. Ghosh, A.; Shcherbik, N. Effects of oxidative stress on protein translation: Implications for cardiovascular diseases. Int. J. Mol. Sci. 2020, 21, 2661. [CrossRef] [PubMed]

52. Ogihara, T.; Asano, T.; Katagiri, H.; Sakoda, H.; Anai, M.; Shojima, N.; Ono, H.; Fujishiro, M.; Kushiyama, A.; Fukushima, Y.; et al. Oxidative stress induces insulin resistance by activating the nuclear factor- $\kappa \mathrm{B}$ pathway and disrupting normal subcellular distribution of phosphatidylinositol 3-kinase. Diabetologia 2004, 47, 794-805. [CrossRef]

53. Tanjore, H.; Xu, X.C.; Polosukhin, V.V.; Degryse, A.L.; Li, B.; Han, W.; Sherrill, T.P.; Plieth, D.; Neilson, E.G.; Blackwell, T.S.; et al. Contribution of epithelial-derived fibroblasts to bleomycin-induced lung fibrosis. Am. J. Respir. Crit. Care Med. 2009, 180, 657-665. [CrossRef]

54. Willis, B.C.; DuBois, R.M.; Borok, Z. Epithelial origin of myofibroblasts during fibrosis in the lung. Proc. Am. Thorac. Soc. 2006, 3, 377-382. [CrossRef]

55. Kirkham, P.A.; Barnes, P.J. Oxidative stress in COPD. Chest 2013, 144, 266-273. [CrossRef]

56. Moylan, J.S.; Reid, M.B. Oxidative stress, chronic disease, and muscle wasting. Muscle Nerve 2007, 35, 411-429. [CrossRef]

57. Mandal, A.K.; Woodi, M.; Sood, V.; Krishnaswamy, P.R.; Rao, A.; Ballal, S.; Balaram, P. Quantitation and characterization of glutathionyl haemoglobin as an oxidative stress marker in chronic renal failure by mass spectrometry. Clin. Biochem. 2007, 40, 986-994. [CrossRef]

58. Dasgupta, A.; Klein, K. Chapter 11-Oxidative Stress Related to Other Diseases. In Antioxidants in Food, Vitamins and Supplements; Dasgupta, A., Klein, K., Eds.; Elsevier: San Diego, CA, USA, 2014; pp. 185-207. [CrossRef]

59. Hussain, T.; Tan, B.; Yin, Y.; Blachier, F.; Tossou, M.C.B.; Rahu, N. Oxidative Stress and Inflammation: What Polyphenols Can Do for Us? Oxid. Med. Cell. Longev. 2016, 2016. [CrossRef] [PubMed]

60. Wing, M.R.; Raj, D.S.; Velasquez, M.T. Protein Energy Metabolism in Chronic Kidney Disease. In Chronic Renal Disease; Academic Press: Cambridge, MA, USA, 2015; pp. 106-125. [CrossRef]

61. Brandtzaeg, P.; Haraldsen, G.; Rugtveit, J. Immunopathology of human inflammatory bowel disease. Springer Semin. Immunopathol. 1997, 18, 555-589. [CrossRef] [PubMed]

62. Smith, G.D.; Watson, R.; Thompson, D.R. Older people and inflammatory bowel disease: A systematic review. J. Clin. Nurs. 2008, 17, 400-406. [CrossRef]

63. Rezaie, A.; Parker, R.D.; Abdollahi, M. Oxidative stress and pathogenesis of inflammatory bowel disease: An epiphenomenon or the cause? Dig. Dis. Sci. 2007, 52, 2015-2021. [CrossRef] [PubMed]

64. Naaber, P.; Mikelsaar, M. Interactions between lactobacilli and antibiotic-associated diarrhea. Adv. Appl. Microbiol. 2004, 54, 231-260.

65. Bratcher, D.F. Other Gram-Positive Bacilli. In Principles and Practice of Pediatric Infectious Diseases; Elsevier: Amsterdam, The Netherlands, 2018; pp. 786-790.e784. [CrossRef]

66. Gu, C.T.; Li, C.Y.; Yang, L.J.; Huo, G.C. Lactobacillus mudanjiangensis sp. nov., Lactobacillus songhuajiangensis sp. nov. and Lactobacillus nenjiangensis sp. nov., isolated from Chinese traditional pickle and sourdough. Int. J. Syst. Evol. Microbiol. 2013, 63, 4698-4706. [CrossRef]

67. Feng, J.; Jiang, Y.; Li, M.; Zhao, S.; Zhang, Y.; Li, X.; Wang, H.; Lin, G.; Wang, H.; Li, T.; et al. Diversity and evolution of Lactobacillus casei group isolated from fermented dairy products in Tibet. Arch. Microbiol. 2018, 200, 1111-1121. [CrossRef] 
68. Švec, P.; Kukletová, M.; Sedláček, I. Comparative evaluation of automated ribotyping and RAPD-PCR for typing of Lactobacillus spp. occurring in dental caries. Anton. Leeuw. 2010, 98, 85-92. [CrossRef]

69. Genus Lactobacillus. Available online: https://lpsn.dsmz.de/genus/lactobacillus (accessed on 9 June 2020).

70. Endo, A.; Futagawa-Endo, Y.; Dicks, L.M.T. Diversity of Lactobacillus and Bifidobacterium in feces of herbivores, omnivores and carnivores. Anaerobe 2010, 16, 590-596. [CrossRef]

71. Liévin-Le Moal, V.; Servin, A.L. Anti-infective activities of Lactobacillus strains in the human intestinal microbiota: From probiotics to gastrointestinal anti- infectious biotherapeutic agents. Clin. Microbiol. Rev. 2014, 27, 167-199. [CrossRef] [PubMed]

72. Kõll-Klais, P.; Mändar, R.; Leibur, E.; Marcotte, H.; Hammarström, L.; Mikelsaar, M. Oral lactobacilli in chronic periodontitis and periodontal health: Species composition and antimicrobial activity. Oral Microbiol. Immunol. 2005, 20, 354-361. [CrossRef]

73. Roos, S.; Engstrand, L.; Jonsson, H. Lactobacillus gastricus sp. nov., Lactobacillus antri sp. nov., Lactobacillus kalixensis sp. nov. and Lactobacillus ultunensis sp. nov., isolated from human stomach mucosa. Int. J. Syst. Evol. Microbiol. 2005, 55, 77-82. [CrossRef] [PubMed]

74. Mitsuoka, T. The Human Gastrointestinal Tract. In The Lactic Acid Bacteria Volume 1: The Lactic Acid Bacteria in Health and Disease; Wood, B.J.B., Ed.; Springer US: Boston, MA, USA, 1992; pp. 69-114. [CrossRef]

75. Goldstein, E.J.C.; Tyrrell, K.L.; Citron, D.M. Lactobacillus species: Taxonomic complexity and controversial susceptibilities. Clin. Infect. Dis. 2015, 60, S98-S107. [CrossRef] [PubMed]

76. Jespers, V.; Menten, J.; Smet, H.; Poradosú, S.; Abdellati, S.; Verhelst, R.; Hardy, L.; Buvé, A.; Crucitti, T. Quantification of bacterial species of the vaginal microbiome in different groups of women, using nucleic acid amplification tests. BMC Microbiol. 2012, 12. [CrossRef] [PubMed]

77. Ni, Y.; Yang, X.; Zheng, L.; Wang, Z.; Wu, L.; Jiang, J.; Yang, T.; Ma, L.; Fu, Z. Lactobacillus and Bifidobacterium Improves Physiological Function and Cognitive Ability in Aged Mice by the Regulation of Gut Microbiota. Mol. Nutr. Food Res. 2019, 63. [CrossRef]

78. Wang, S.; Ahmadi, S.; Nagpal, R.; Jain, S.; Mishra, S.P.; Kavanagh, K.; Zhu, X.; Wang, Z.; McClain, D.A.; Kritchevsky, S.B.; et al. Lipoteichoic acid from the cell wall of a heat killed Lactobacillus paracasei D3-5 ameliorates aging-related leaky gut, inflammation and improves physical and cognitive functions: From C. elegans to mice. GeroScience 2020, 42, 333-352. [CrossRef]

79. Aabed, K.; Shafi Bhat, R.; Moubayed, N.; Al-Mutiri, M.; Al-Marshoud, M.; Al-Qahtani, A.; Ansary, A. Ameliorative effect of probiotics (Lactobacillus paracaseii and Protexin ${ }^{\circledR}$ ) and prebiotics (propolis and bee pollen) on clindamycin and propionic acid-induced oxidative stress and altered gut microbiota in a rodent model of autism. Cell. Mol. Biol. (Noisy-le-Grand) 2019, 65, 1-7. [CrossRef]

80. Truusalu, K.; Naaber, P.; Kullisaar, T.; Tamm, H.; Mikelsaar, R.H.; Zilmer, K.; Rehema, A.; Zilmer, M.; Mikelsaar, M. The influence of antibacterial and antioxidative probiotic lactobacilli on gut mucosa in a mouse model of Salmonella infection. Microb. Ecol. Health Dis. 2004, 16, 180-187. [CrossRef]

81. Jones, R.M.; Mercante, J.W.; Neish, A.S. Reactive oxygen production induced by the gut microbiota: Pharmacotherapeutic Implications. Curr. Med. Chem. 2012, 19, 1519-1529. [CrossRef]

82. Allen, R.G.; Tresini, M. Oxidative stress and gene regulation. Free Radic. Biol. Med. 2000, 28, 463-499. [CrossRef]

83. An, H.; Zhai, Z.; Yin, S.; Luo, Y.; Han, B.; Hao, Y. Coexpression of the superoxide dismutase and the catalase provides remarkable oxidative stress resistance in Lactobacillus rhamnosus. J. Agric. Food Chem. 2011, 59, 3851-3856. [CrossRef] [PubMed]

84. Wang, G.; Yin, S.; An, H.; Chen, S.; Hao, Y. Coexpression of bile salt hydrolase gene and catalase gene remarkably improves oxidative stress and bile salt resistance in Lactobacillus casei. J. Ind. Microbiol. Biotechnol. 2011, 38, 985-990. [CrossRef] [PubMed]

85. Mariela, L.M.; Molenaar, D.; Wels, M.; Teusink, B.; Bron, P.A.; de Vos, W.M.; Smid, E.J. Thioredoxin reductase is a key factor in the oxidative stress response of Lactobacillus plantarum WCFS1. Microb. Cell Fact. 2007, 6. [CrossRef] 
86. Lin, J.; Zou, Y.; Cao, K.; Ma, C.; Chen, Z. The impact of heterologous catalase expression and superoxide dismutase overexpression on enhancing the oxidative resistance in Lactobacillus casei. J. Ind. Microbiol. Biotechnol. 2016, 43, 703-711. [CrossRef]

87. Zhai, Z.; Yang, Y.; Wang, J.; Wang, G.; Ren, F.; Hao, Y. Complete genome sequencing of Lactobacillus plantarum CAUH2 reveals a novel plasmid pCAUH203 associated with oxidative stress tolerance. 3 Biotech $2019,9$. [CrossRef]

88. Serata, M.; Iino, T.; Yasuda, E.; Sako, T. Roles of thioredoxin and thioredoxin reductase in the resistance to oxidative stress in Lactobacillus casei. Microbiology 2012, 158, 953-962. [CrossRef]

89. Serata, M.; Kiwaki, M.; Iino, T. Functional analysis of a novel hydrogen peroxide resistance gene in Lactobacillus casei strain Shirota. Microbiology 2016, 162, 1885-1894. [CrossRef]

90. Cappa, F.; Cattivelli, D.; Cocconcelli, P.S. The uvrA gene is involved in oxidative and acid stress responses in Lactobacillus helveticus CNBL1156. Res. Microbiol. 2005, 156, 1039-1047. [CrossRef] [PubMed]

91. Chen, L.; Gu, Q.; Li, P.; Chen, S.; Li, Y. Genomic analysis of Lactobacillus reuteri WHH1689 reveals its probiotic properties and stress resistance. Food Sci. Nutr. 2019, 7, 844-857. [CrossRef]

92. Ma, Q. Role of Nrf2 in oxidative stress and toxicity. Annu. Rev. Pharmacol. Toxicol. 2013, 53, 401-426. [CrossRef]

93. Hayes, J.D.; McMahon, M.; Chowdhry, S.; Dinkova-Kostova, A.T. Cancer chemoprevention mechanisms mediated through the keap1-Nrf2 pathway. Antioxid. Redox Signal. 2010, 13, 1713-1748. [CrossRef] [PubMed]

94. Kobatake, E.; Nakagawa, H.; Seki, T.; Miyazaki, T. Protective effects and functional mechanisms of Lactobacillus gasseri SBT2055 against oxidative stress. PLoS ONE 2017, 12, e0177106. [CrossRef]

95. Taguchi, K.; Motohashi, H.; Yamamoto, M. Molecular mechanisms of the Keap1-Nrf2 pathway in stress response and cancer evolution. Genes Cells 2011, 16, 123-140. [CrossRef]

96. Winyard, P.G.; Moody, C.J.; Jacob, C. Oxidative activation of antioxidant defence. Trends Biochem. Sci. 2005, 30, 453-461. [CrossRef]

97. Singh, S.; Sharma, R.K.; Malhotra, S.; Pothuraju, R.; Shandilya, U.K. Lactobacillus rhamnosus NCDC17 ameliorates type-2 diabetes by improving gut function, oxidative stress and inflammation in high-fat-diet fed and streptozotocintreated rats. Benef. Microbes 2017, 8, 243-255. [CrossRef] [PubMed]

98. Li, B.; Evivie, S.E.; Lu, J.; Jiao, Y.; Wang, C.; Li, Z.; Liu, F.; Huo, G. Lactobacillus helveticus KLDS1.8701 alleviates d-galactose-induced aging by regulating Nrf-2 and gut microbiota in mice. Food Funct. 2018, 9, 6586-6598. [CrossRef]

99. Finamore, A.; Ambra, R.; Nobili, F.; Garaguso, I.; Raguzzini, A.; Serafini, M. Redox role of Lactobacillus casei shirota against the cellular damage induced by 2,2'-azobis (2-amidinopropane) dihydrochloride-induced oxidative and inflammatory stress in enterocytes-like epithelial cells. Front. Immunol. 2018, 9. [CrossRef]

100. Pan, H.; Wang, H.; Wang, X.; Zhu, L.; Mao, L. The absence of Nrf2 enhances NF-kB-dependent inflammation following scratch injury in mouse primary cultured astrocytes. Mediat. Inflamm. 2012, 2012. [CrossRef] [PubMed]

101. Thimmulappa, R.K.; Lee, H.; Rangasamy, T.; Reddy, S.P.; Yamamoto, M.; Kensler, T.W.; Biswal, S. Nrf2 is a critical regulator of the innate immune response and survival during experimental sepsis. J. Clin. Investig. 2006, 116, 984-995. [CrossRef]

102. Staal, F.J.T.; Roederer, M.; Herzenberg, L.A.; Herzenberg, L.A. Intracellular thiols regulate activation of nuclear factor kB and transcription of human immunodeficiency virus. Proc. Natl. Acad. Sci. USA 1990, 87, $9943-9947$. [CrossRef] [PubMed]

103. Djavaheri-Mergny, M.; Javelaud, D.; Wietzerbin, J.; Besançon, F. NF- $\kappa$ B activation prevents apoptotic oxidative stress via an increase of both thioredoxin and MnSOD levels in TNF $\alpha$-treated Ewing sarcoma cells. FEBS Lett. 2004, 578, 111-115. [CrossRef] [PubMed]

104. Song, C.; Mitter, S.K.; Qi, X.; Beli, E.; Rao, H.V.; Ding, J.; Ip, C.S.; Gu, H.; Akin, D.; Dunn, W.A.; et al. Oxidative stress-mediated NF-kB phosphorylation upregulates p62/SQSTM1 and promotes retinal pigmented epithelial cell survival through increased autophagy. PLOS ONE 2017, 12, e0171940. [CrossRef]

105. Chen, L.; Liu, W.; Li, Y.; Luo, S.; Liu, Q.; Zhong, Y.; Jian, Z.; Bao, M. Lactobacillus acidophilus ATCC 4356 attenuates the atherosclerotic progression through modulation of oxidative stress and inflammatory process. Int. Immunopharmacol. 2013, 17, 108-115. [CrossRef] 
106. Jiang, X.; Gu, S.; Liu, D.; Zhao, L.; Xia, S.; He, X.; Chen, H.; Ge, J. Lactobacillus brevis 23017 relieves mercury toxicity in the colon by modulation of oxidative stress and inflammation through the interplay of MAPK and NF-кB signaling cascades. Front. Microbiol. 2018, 9. [CrossRef]

107. Hou, C.L.; Zhang, J.; Liu, X.T.; Liu, H.; Zeng, X.F.; Qiao, S.Y. Superoxide dismutase recombinant Lactobacillus fermentum ameliorates intestinal oxidative stress through inhibiting NF- $\mathrm{B}$ activation in a trinitrobenzene sulphonic acid-induced colitis mouse model. J. Appl. Microbiol. 2014, 116, 1621-1631. [CrossRef]

108. Toral, M.; Romero, M.; Rodríguez-Nogales, A.; Jiménez, R.; Robles-Vera, I.; Algieri, F.; Chueca-Porcuna, N.; Sánchez, M.; de la Visitación, N.; Olivares, M.; et al. Lactobacillus fermentum Improves Tacrolimus-Induced Hypertension by Restoring Vascular Redox State and Improving eNOS Coupling. Mol. Nutr. Food Res. $2018,62$. [CrossRef]

109. Faria, A.M.; Papadimitriou, A.; Silva, K.C.; Lopes De Faria, J.M.; Lopes De Faria, J.B. Uncoupling endothelial nitric oxide synthase is ameliorated by green tea in experimental diabetes by re-establishing tetrahydrobiopterin levels. Diabetes 2012, 61, 1838-1847. [CrossRef]

110. Wang, Y.; Guo, Y.; Chen, H.; Wei, H.; Wan, C. Potential of Lactobacillus plantarum ZDY2013 and Bifidobacterium bifidum WBIN03 in relieving colitis by gut microbiota, immune, and anti-oxidative stress. Can. J. Microbiol. 2018, 64, 327-337. [CrossRef]

111. Li, B.; Du, P.; Smith, E.E.; Wang, S.; Jiao, Y.; Guo, L.; Huo, G.; Liu, F. In vitro and in vivo evaluation of an exopolysaccharide produced by Lactobacillus helveticus KLDS1.8701 for the alleviative effect on oxidative stress. Food Funct. 2019, 10, 1707-1717. [CrossRef]

112. Ghosh, S.; Van Heel, D.; Playford, R.J. Probiotics in inflammatory bowel disease: Is it all gut flora modulation? Gut 2004, 53, 620-622. [CrossRef] [PubMed]

113. Palócz, O.; Pászti-Gere, E.; Gálfi, P.; Farkas, O. Chlorogenic acid combined with Lactobacillus plantarum 2142 reduced LPS-induced intestinal inflammation and oxidative stress in IPEC-J2 cells. PLoS ONE 2016, 11, e0166642. [CrossRef]

114. Le, B.; Yang, S.H. Efficacy of Lactobacillus plantarum in prevention of inflammatory bowel disease. Toxicol. Rep. 2018, 5, 314-317. [CrossRef] [PubMed]

115. Hrdý, J.; Alard, J.; Couturier-Maillard, A.; Boulard, O.; Boutillier, D.; Delacre, M.; Lapadatescu, C.; Cesaro, A.; Blanc, P.; Pot, B.; et al. Lactobacillus reuteri 5454 and Bifidobacterium animalis ssp. lactis 5764 improve colitis while differentially impacting dendritic cells maturation and antimicrobial responses. Sci. Rep. 2020, 10. [CrossRef] [PubMed]

116. Forsyth, C.B.; Farhadi, A.; Jakate, S.M.; Tang, Y.; Shaikh, M.; Keshavarzian, A. Lactobacillus GG treatment ameliorates alcohol-induced intestinal oxidative stress, gut leakiness, and liver injury in a rat model of alcoholic steatohepatitis. Alcohol 2009, 43, 163-172. [CrossRef]

117. Wang, A.N.; Cai, C.J.; Zeng, X.F.; Zhang, F.R.; Zhang, G.L.; Thacker, P.A.; Wang, J.J.; Qiao, S.Y. Dietary supplementation with Lactobacillus fermentum 15007 improves the anti-oxidative activity of weanling piglets challenged with diquat. J. Appl. Microbiol. 2013, 114, 1582-1591. [CrossRef]

118. Tian, X.; Yu, Z.; Feng, P.; Ye, Z.; Li, R.; Liu, J.; Hu, J.; Kakade, A.; Liu, P.; Li, X. Lactobacillus plantarum TW1-1 alleviates diethylhexylphthalate-induced testicular damage in mice by modulating gut microbiota and decreasing inflammation. Front. Cell. Infect. Microb. 2019, 9. [CrossRef]

119. Ardeshirlarijani, E.; Tabatabaei-Malazy, O.; Mohseni, S.; Qorbani, M.; Larijani, B.; Baradar Jalili, R. Effect of probiotics supplementation on glucose and oxidative stress in type 2 diabetes mellitus: A meta-analysis of randomized trials. Daru 2019, 27, 827-837. [CrossRef]

120. Robles-Vera, I.; Toral, M.; de la Visitación, N.; Sánchez, M.; Romero, M.; Olivares, M.; Jiménez, R.; Duarte, J. The Probiotic Lactobacillus fermentum Prevents Dysbiosis and Vascular Oxidative Stress in Rats with Hypertension Induced by Chronic Nitric Oxide Blockade. Mol. Nutr. Food Res. 2018, 62. [CrossRef]

121. Huang, W.C.; Wei, C.C.; Huang, C.C.; Chen, W.L.; Huang, H.Y. The beneficial effects of Lactobacillus plantarum PS128 on high-intensity, exercise-induced oxidative stress, inflammation, and performance in triathletes. Nutrients 2019, 11, 353. [CrossRef] 
122. Yu, L.; Zhai, Q.; Tian, F.; Liu, X.; Wang, G.; Zhao, J.; Zhang, H.; Narbad, A.; Chen, W. Potential of Lactobacillus plantarum CCFM639 in protecting against aluminum toxicity mediated by intestinal barrier function and oxidative stress. Nutrients 2016, 8, 783. [CrossRef] [PubMed]

123. Deol, P.K.; Khare, P.; Bishnoi, M.; Kondepudi, K.K.; Kaur, I.P. Coadministration of ginger extract-Lactobacillus acidophilus (cobiotic) reduces gut inflammation and oxidative stress via downregulation of COX-2, i-NOS, and c-Myc. Phytother. Res. 2018, 32, 1950-1956. [CrossRef] [PubMed]

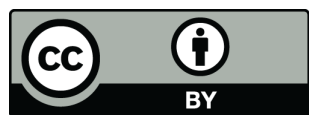

(C) 2020 by the authors. Licensee MDPI, Basel, Switzerland. This article is an open access article distributed under the terms and conditions of the Creative Commons Attribution (CC BY) license (http://creativecommons.org/licenses/by/4.0/). 